Article

\title{
Research on Vacuum Arc Commutation Characteristics of a Natural-Commutate Hybrid DC Circuit Breaker
}

\author{
Dequan Wang, Minfu Liao *, Rufan Wang, Tenghui Li, Jun Qiu, Jinjin Li, Xiongying Duan * and \\ Jiyan Zou \\ School of Electrical Engineering, Dalian University of Technology, Dalian 116024, China; \\ wdq@mail.dlut.edu.cn (D.W.); Wangrufan@mail.dlut.edu.cn (R.W.); litenghui@mail.dlut.edu.cn (T.L.); \\ qjun@mail.dlut.edu.cn (J.Q.); jinjinli@mail.dlut.edu.cn (J.L.); jyzou@dlut.edu.cn (J.Z.) \\ * Correspondence: LMF@dlut.edu.cn (M.L.); dxy@dlut.edu.cn (X.D.); Tel.: +86-198-1899-7875 (M.L.)
}

Received: 8 August 2020; Accepted: 12 September 2020; Published: 15 September 2020

\begin{abstract}
Vacuum arc commutation is an important process in natural-commutate hybrid direct current (DC) circuit breaker (NHCB) interruption, as the duration of vacuum arc commutation will directly affect the arcing time and interrupting time of NHCB. In this paper, the vacuum arc commutation model of NHCB was established by simplifying solid-state switch (SS) and vacuum arc voltage. Through theoretical analysis and experiments, the vacuum arc commutation characteristics of NHCB were studied. The mathematical formula of the effect of main parameters on the duration of vacuum arc commutation is obtained, and the changing law of the influence of the main parameters on the duration of the vacuum arc commutation is explored. The concept of vacuum arc commutation coefficient is proposed, and it is a key parameter that influences the vacuum arc commutation characteristics. The research on the characteristics of vacuum arc commutation can provide theoretical foundation for the structure and parameter optimization of NHCB and other equipment that uses vacuum arc commutation.
\end{abstract}

Keywords: hybrid dc circuit breaker; vacuum arc commutation; solid-state switch; vacuum arc voltage

\section{Introduction}

With the development of fully controlled power electronic devices (FPEDs), such as the gate turn-off thyristor (GTO), insulated gate bipolar transistor (IGBT), integrated gate commutated thyristor (IGCT), and injection-enhanced gate transistor (IEGT), the hybrid direct current (DC) circuit breaker based on power electronic technology has become an important technical solution and research hotspot for DC breaking [1-4]. This type of DC circuit breaker combines the advantages of solid-state switches (SSs) and mechanical switches (MSs), and shows the characteristics of a strong current carrying capacity, low on-state loss, fast breaking speed, and no need for cooling devices $[5,6]$.

According to the difference of the current commutating method from MS to SS, hybrid DC circuit breakers based on power electronics technology are divided into forced-commutate hybrid DC circuit breakers (FHCBs) and natural-commutate hybrid DC circuit breakers (NHCBs) [7,8]. The FHCB is mostly used in the field of voltage above $10 \mathrm{kV}[9,10]$, and one of the most representative FHCBs is the $320 \mathrm{kV} / 2.6 \mathrm{kA}$ hybrid DC circuit breaker developed by ABB in 2011 [11]. NHCB is mostly used in the voltage field of $10 \mathrm{kv}$ and below, and there has been a lot of research on the NHCB [12]. Genji et al. [13] proposed the NHCB firstly in 1994, and SS of NHCB is mainly composed of GTO. Polman et al. [14] developed a 600V NHCB by fast MS and IGBTs in 2001, and it is a bi-directional switch. Luca Novello et al. [15] developed a prototype of $1 \mathrm{kV} / 10 \mathrm{kA}$ NHCB by using IGCT's series and 
parallel technology in 2011. Lv gang et al. [16] studied the vacuum arc commutation characteristics of NHCB, and a $10 \mathrm{kV} / 3.5 \mathrm{kA}$ NHDB prototype was designed and tested.

There have been some studies on the vacuum arc commutation characteristics of NHCB. The vacuum arc commutation model was constructed in [16,17], and the theoretical calculation formula of the rate of the current rise in the commutation branch is given. In [18], a theoretical analysis model is established, and the influence of adding impedance on vacuum arc commutation was studied. The authors of [19] simplified an equivalent treatment of the IGBT module in SS, and the criteria of the vacuum arc commutation were obtained. The authors of [15] studied the vacuum arc characteristics at different breaking distances and different currents. The authors of [20] studied the two current commutation measures for hybrid DC circuit breakers, and proposed a new current commutation measure. The authors of [21] studied the influence of internal and external factors on vacuum arc commutation, and reasonable parameters that can promote vacuum arc commutation were summarized.

The duration of vacuum arc commutation is a very important parameter, as it will directly affect the arcing time and interrupting time of $\mathrm{NHCB}$, and shortening it will facilitate the interruption of NHCB. However, little work has focused on the duration of vacuum arc commutation, and, especially, there is a lack of mathematical formulas about it. In this regard, we conducted research on the vacuum arc commutation characteristics of $\mathrm{NHCB}$, and focused on the influence of the main parameters on the duration of vacuum arc commutation. Section 2 establishes a simplified vacuum arc commutation model of $\mathrm{NHCB}$, and theoretically derives the influence of the main parameters on the vacuum arc commutation characteristics. Sections 3 and 4 establish a vacuum arc commutation test circuit, and experimentally study the influence of the main parameters on the vacuum arc commutation characteristics. Section 5 first discusses the theoretical derivation and experimental results of the previous two sections, proposes the concept of the vacuum arc commutation coefficient, and then discusses the influence of the main parameters on the vacuum arc voltage. Finally, Section 6 concludes this paper.

\section{Theoretical Analysis}

\subsection{Principle of $\mathrm{NHCB}$}

As shown in Figure 1, an NHCB mainly includes an MS, an SS and a metal-oxide varistor (MOV) [14]. The current limiting reactor is mainly used to limit the fault current. SS is mainly composed of FPEDs through series and parallel connection, and the most commonly used FPEDs are GTO, IGCT, IGBT, and IEGT. According to the literature [9], the interruption process of NHCB mainly includes vacuum arc commutation and the interruption process of SS. The interruption process of NHCB is shown in Figure 2. In this paper, we will focus on the vacuum arc commutation during NHCB interruption. $I_{m}, I_{s}$, and $I_{m o v}$ represent the currents of the MS, SS, and MOV, respectively.

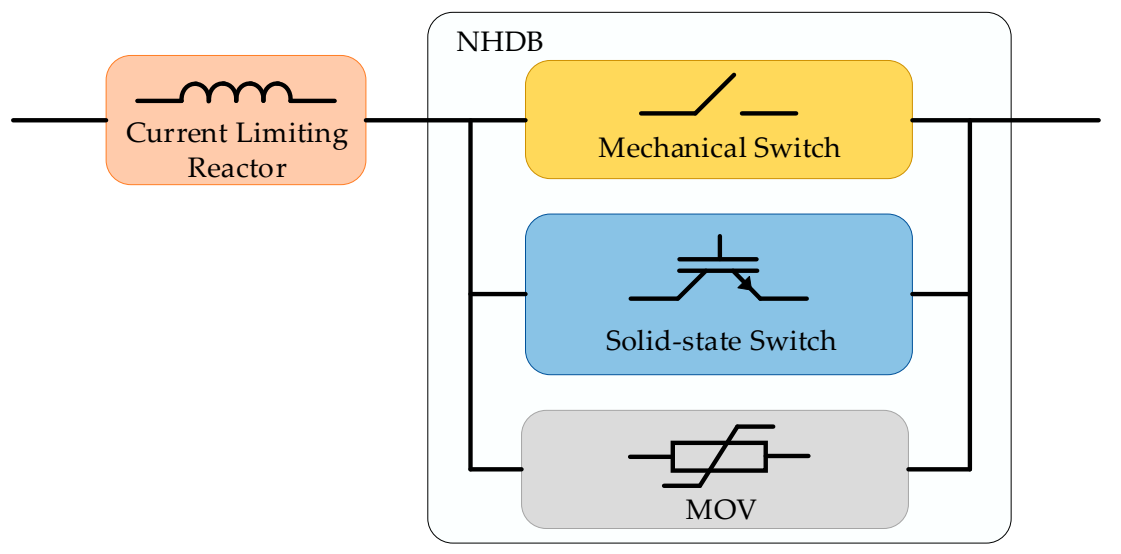

Figure 1. The schematic of a natural-commutate hybrid DC circuit breaker (NHCB). 


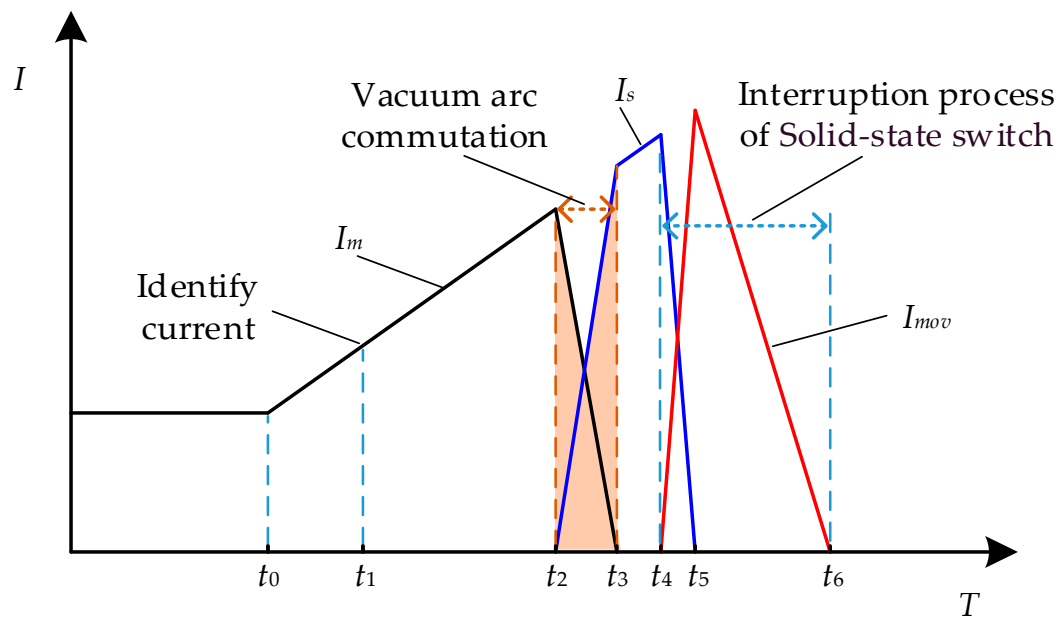

Figure 2. Interruption process of NHCB.

\subsection{Vacuum Arc Commutation Model}

The typical waveform of the vacuum arc commutation is shown in Figure 3 [18]. According to the research of the literature [16,17], the vacuum arc commutation model of NHCB is shown in Figure $4 \mathrm{a}$. Then, according to the model shown in Figure $4 \mathrm{a}$, the vacuum arc commutation should follow Formula (1). As shown in Formula (2), Formula (1) can be further rewritten as the relational expression about the current commutating speed $\mathrm{d} I_{c} / \mathrm{d} t_{c}$. $U_{\text {arc }}$ represents the vacuum arc voltage. $U_{s e}$ represents the on-state voltage of the SS at the end of vacuum arc commutation. $L_{S}$ represents the stray inductance of the SS. $I_{n}$ represents the currents of NHCB. $I_{S i}$ represents the current of the SS at the initial moment of vacuum arc commutation. $I_{s e}$ represents the current of the SS at the end of vacuum arc commutation. $I_{\mathcal{C}}$ is called the commutation current, which represents the current commutated to the SS during the vacuum arc commutation. $I_{\mathcal{c} e}$ is called the final commutation current, which represents the current commutated to the SS from the beginning to the end of the vacuum arc commutation. $t_{c}$ represents the time it takes for the commutation current to increase from zero to $I_{c}$. $T_{c}$ represents the duration of vacuum arc commutation.

$$
\begin{aligned}
& U_{\text {arc }}=L_{s} \frac{\mathrm{d} I_{c}}{\mathrm{~d} t_{c}}+U_{s} 0 \leq I_{c} \leq I_{c e}, \\
& \frac{\mathrm{d} I_{c}}{\mathrm{~d} t_{\mathcal{c}}}=\frac{U_{a r c}-U_{s}}{L_{s}} 0 \leq I_{\mathcal{c}} \leq I_{c e}
\end{aligned}
$$

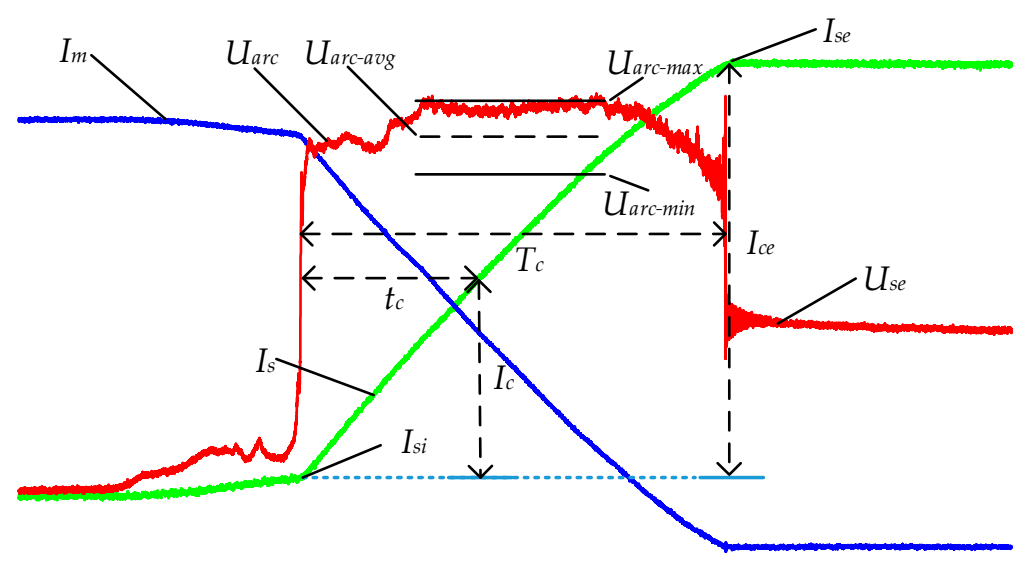

Figure 3. Example of typical vacuum arc commutation. 


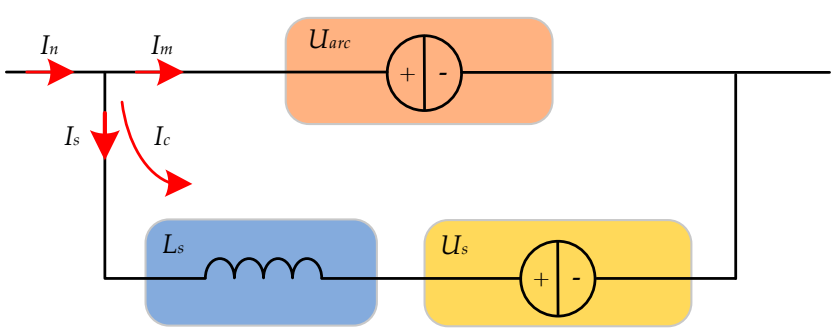

(a)

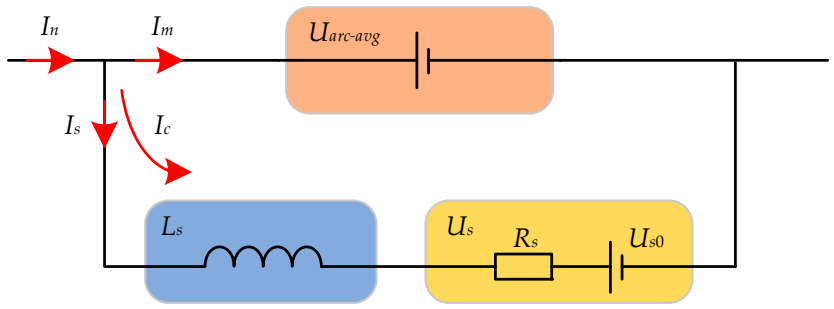

(b)

Figure 4. The vacuum arc commutation model of NHCB (a) before and (b) after simplification.

For FPEDs, such as IGBT, IGCT, and IEGT, the relationship between their on-state voltage $U_{\mathrm{CE}}$ and collector current $I$ is shown in Formula (3) [22]. As shown in Figure 5, the value of their on-state voltage $U_{C E}$ is basically linear with the collector current $I$. Therefore, as shown in Figure 5, the relationship between $U_{C E}$ and $I$ can be linearly processed, and the relationship between $U_{C E}$ and $I$ is obtained as shown in Formula (4). Because SSs are made of FPEDs through series and parallel connection, the relationship between $U_{s}$ and $I_{s}$ can also be obtained as shown in Formula (5). $U_{\mathrm{CE} 0}$ represents the on-state voltage of the FPEDs when the collector current is zero. $r$ represents the on-state resistance of the FPEDs. $U_{0}$ represents the approximate on-state voltage of the FPEDs when the collector current is zero. $R$ represents the approximate on-state resistance of the FPEDs. $U_{s 0}$ represents the approximate on-state voltage of the SS when the $I_{S}$ is zero:

$$
\begin{gathered}
U_{C E}=U_{C E 0}+r I, \\
U_{C E}=U_{0}+R I, \\
U_{s}=U_{s 0}+R_{s} I_{s} .
\end{gathered}
$$

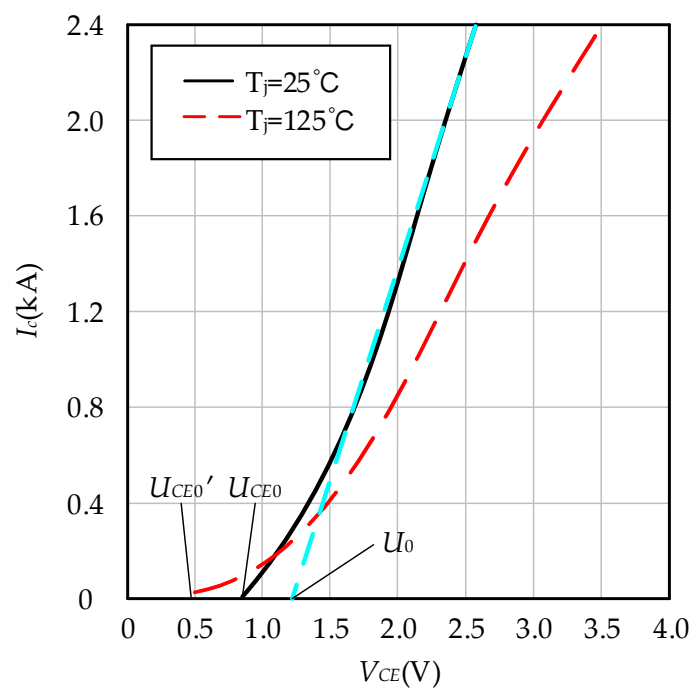

Figure 5. Collector-emitter saturation voltage characteristics of FZ1200R17HP4_B2 [23]. 
As shown in Figure 3, because the change in the vacuum arc voltage is relatively small during the vacuum arc commutation [24], $U_{\text {arc-avg }}$ can be taken as the vacuum arc voltage value, and $U_{\text {arc-avg }}$ is the average value of the maximum value $U_{\text {arc-max }}$ and the minimum value $U_{\text {arc-min }}$ of the vacuum arc voltage. According to Formula (5), the model shown in Figure 4a can be rewritten as shown in Figure $4 \mathrm{~b}$. Then, according to the model shown in Figure $4 \mathrm{~b}$, the vacuum arc commutation should follow Formula (6). It is easy to know that $I_{s}=I_{s i}+I_{c}$, and according to Formula (5), the system of equations shown in Formula (7) can be easily obtained. $U_{s i}$ represents the on-state voltage of the SS at the initial moment of vacuum arc commutation:

$$
\begin{aligned}
& \frac{\mathrm{d} I_{c}}{\mathrm{~d} t_{c}}=\frac{U_{\text {arc-avg }}-U_{s}}{L_{s}} 0 \leq I_{c} \leq I_{c e}, \\
& \left\{\begin{array}{l}
U_{s i}=U_{s 0}+R_{s} I_{s i} \\
U_{s}=U_{s i}+R_{s} I_{c} 0 \leq I_{c} \leq I_{c e}
\end{array} .\right.
\end{aligned}
$$

After solving Formulas (6) and (7), the relationship expression of $t_{c}$ about $I_{c}$ is obtained as shown in Formula (8). It is easy to know that when $I_{c}=I_{c e}, t_{c}=T_{c}$, then according to Formula (8), the relationship between $T_{c}$ and $I_{c e}$ can be obtained as shown in Formula (9). From Formula (9), we can see that $L_{s}$, $R_{s}, I_{c e}, U_{\text {arc-avg }}$, and $U_{s i}$ are the main parameters that affect $T_{c}$. Meanwhile, according to Formula (6), if $\mathrm{d} I_{c} / \mathrm{d} t_{c} \leq 0$, the current will stop commuting to the $S S$ branch, so $\mathrm{d} I_{c} / \mathrm{d} t_{c}>0$ should always be ensured during the vacuum arc commutation. By solving $\mathrm{d} I_{c} / \mathrm{d} t_{c}>0$, Formula (10) can be obtained:

$$
\begin{gathered}
t_{c}=-\frac{L_{s}}{R_{s}} \ln \left(\frac{U_{\text {arc-avg }}-U_{s i}-R_{s} I_{c}}{U_{\text {arc-avg }}-U_{s i}}\right) 0 \leq I_{c} \leq I_{c e}, \\
T_{c}=-\frac{L_{s}}{R_{s}} \ln \left(\frac{U_{\text {arc-avg }}-U_{s i}-R_{s} I_{c e}}{U_{\text {arc-avg }}-U_{s i}}\right), \\
U_{\text {arc-avg }}-U_{s i}-R_{s} I_{c e}>0 .
\end{gathered}
$$

\subsection{Influence of Main Parameters on Vacuum Arc Commutation Characteristics}

In this section, the effects of parameters, such as $L_{s}, R_{s}, I_{c e}, U_{\text {arc-avg, }}$ and $U_{s i}$, on $T_{c}$ are further studied. Firstly, it is easy to know from Formula (9), under the condition that other parameters remain unchanged, $T_{c}$ has a linear relationship with $L_{s}$.

Assuming that the parameters $L_{s}$ and $R_{s}$ remain unchanged and $L_{s} / R_{s}=\mathrm{b}$, let $k=\left(U_{\text {arc-avg }}-\right.$ $\left.U_{s i}\right) / R_{s} I_{c e}$, then as shown in Formula (11), Formula (9) can be further rewritten as a function about $k$, and it is easy to know from Formula (10) that $k>1$ :

$$
T_{c}=-\mathrm{b} \cdot \ln \left(1-\frac{1}{k}\right) k>1
$$

It is easy to know that changing the parameters $U_{\text {arc-avg }}, U_{s i}$, and $I_{c e}$ is equivalent to changing the parameter $k$, and the relationship curve between $T_{c}$ and $k$ is plotted according to Formula (11), as shown in Figure 6. It can be seen from Figure $6, T_{c}$ decreases with increasing $k$, but the rate of decrease becomes slower and slower and even tends to be constant. $k$ is the ratio of the parameters $U_{\text {arc-avg }}-U_{s i}$ and $R_{s} I_{c e}$.

Assuming that the parameters $L_{s}, I_{c e}, U_{\text {arc-avg }}$ and $U_{s i}$ remain unchanged and $L_{s}=\mathrm{a}$, the variation of $T_{C}$ with $R_{S}$ is explored. Let the value of $R_{S}$ at the initial time be a fixed value $R_{s 0}$. Correspondingly, $k=\left(U_{\text {arc }-a v g}-U_{s i}\right) / R_{s 0} I_{c e}=k_{0}$; let the changed $R_{s}=x R_{s 0}$, and correspondingly, $k=\left(U_{\text {arc-avg }}-U_{s i}\right) / x R_{s 0} I_{c e}$ $=k_{0} / x$. Then, as shown in Formula (12), Formula (9) can be further rewritten as a function about $x$, and it is easy to know from Formula (10) that $x<k_{0}$ :

$$
T_{c}=-\frac{\mathrm{a}}{x} \ln \left(1-\frac{x}{k_{0}}\right) x<k_{0}
$$


When $k_{0}$ takes the values of 4 and 8, respectively, as shown in Figure 7 , the variation curves of $T_{\mathcal{C}}$ and $k$ are plotted with $x$ according to Formula (12). It can be seen from Figure $7, T_{c}$ increases with increasing $x$, and the rate of increase becomes faster and faster; $k$ decreases with increasing $x$, but the rate of decrease becomes slower and slower. The change curve of $T_{\mathcal{c}}$ with $k$ is plotted in Figure 7 as shown in Figure 8. As it can be seen from Figure $8, T_{\mathcal{c}}$ decreases with increasing $k$, but the rate of decrease becomes slower and slower and even tends to be constant. $k_{0}$ is the ratio of the parameters $U_{\text {arc-avg }}-U_{s i}$ and $R_{s 0} I_{c e}$, and $R_{s 0}$ is the initial value of $R_{s}$.

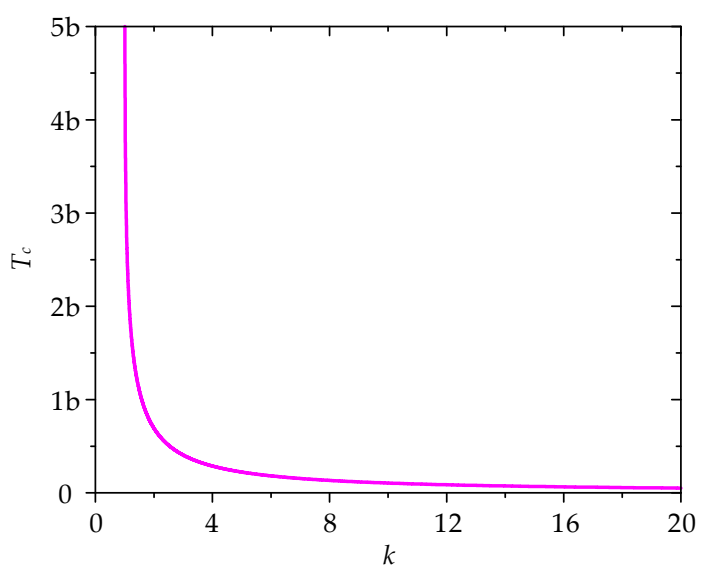

Figure 6. The relationship curve between $t_{c}$ and $k$.

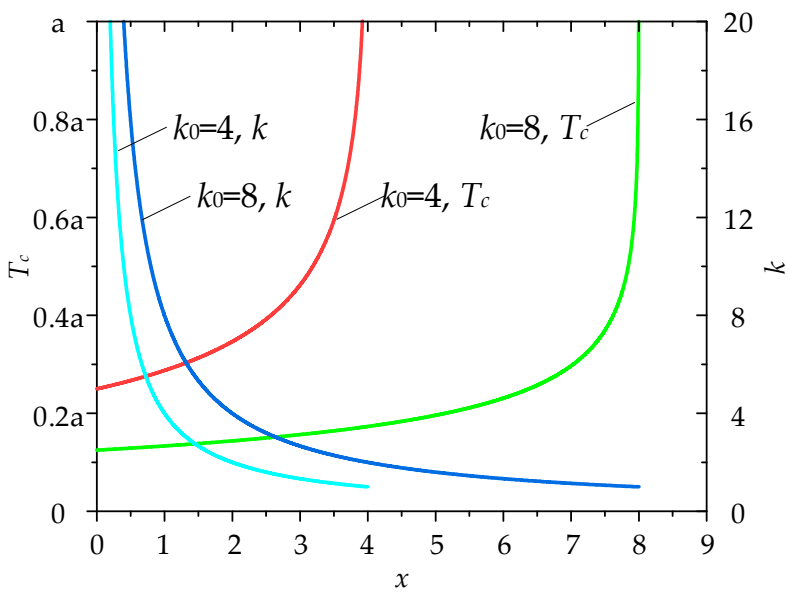

Figure 7. The variation curves of $T_{c}$ and $k$ with $x$.

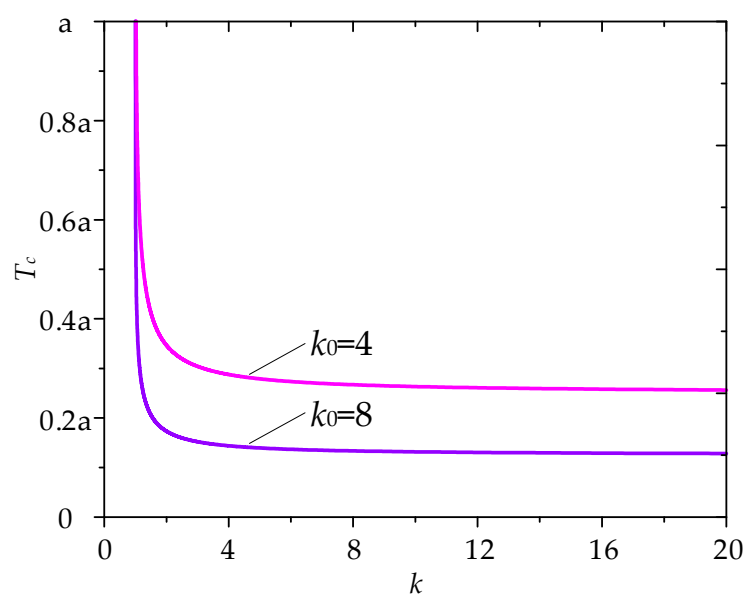

Figure 8. The relationship curve between $T_{c}$ and $k$ in Figure 7. 
It can be seen from Figures 6 and 8 that when $k$ is small, $T_{c}$ changes greatly with the increase of $k$, and when $k$ is large, $T_{c}$ changes little or even tends to be constant with the increase of $k$; therefore, the larger the value of $k$, the more effective it is to reduce the value of $T_{c}$.

\section{Test Configuration}

As shown in Figure 9, the test platform is mainly composed of an $L C$ oscillation circuit, NHCB, controller, and data acquisition system. The $L C$ oscillation circuit is composed of a capacitor $C_{i}$ and an inductance $L_{i}$, and is mainly used to generate the large current required for the experiment. $K_{m}$ is the experimental control switch, responsible for introducing current into NHCB. $K_{v}$ represents the MS of NHCB. The SS of NHCB is mainly composed of impedance $Z_{a}$ and the IGBT module, and the impedance $Z_{a}$ is formed by the inductance $L_{a}$ and the resistance $R_{a}$ in series. The on-state resistance and stray inductance of the SS are changed by changing $R_{a}$ and $L_{a}$, respectively, to explore the effects of on-state resistance and stray inductance on vacuum arc commutation characteristics of NHCB. The IGBT selected in this experiment is CM1000HA-24H, the collector current of a single CM1000HA-24H is up to $2 \mathrm{kA}$, and two IGBTs are connected in parallel to form an IGBT module. $C_{t 1}$ and $C_{t 2}$ are current sensors, which are used to collect the currents of the MS and SS branches, respectively. $P_{t}$ is a voltage sensor used to collect the vacuum arc voltage. The controller is used to control the operation sequence of the entire experiment. The data acquisition system is used for data collection and display.

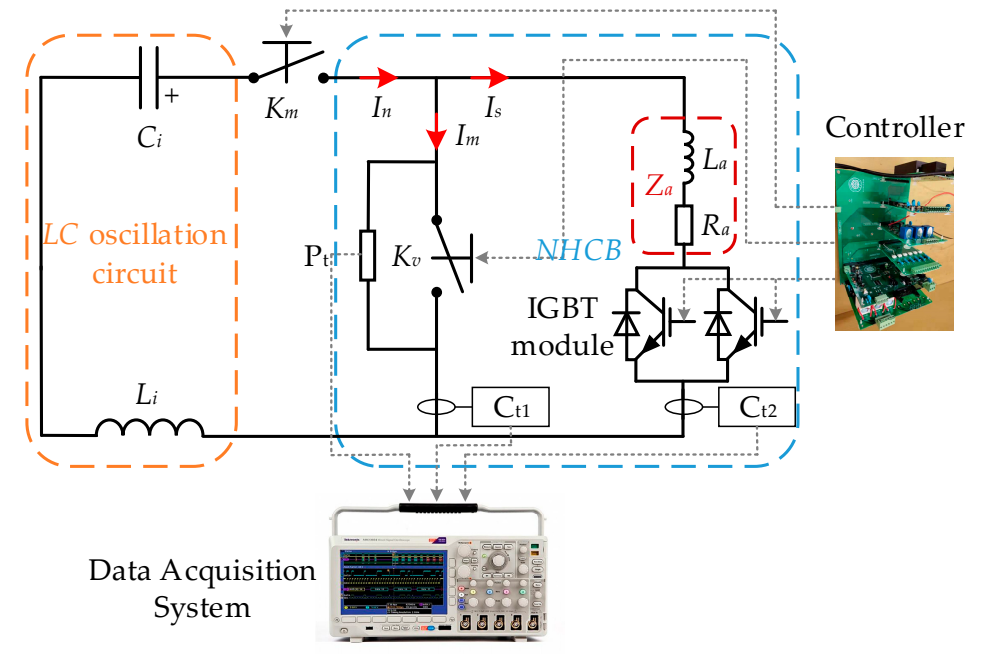

Figure 9. Vacuum arc commutation test platform.

\section{Experimental Results}

\subsection{Influence of Stray Inductance of the SS}

Under the condition that $R_{a}$ is $5 \mathrm{~m} \Omega$, and $I_{s e}$ is approximately $0.5,1$, and $1.5 \mathrm{kA}$, respectively, we obtained the waveforms of vacuum arc commutation with different stray inductances. When the $I_{s e}$ is approximately $1 \mathrm{kA}$, the waveforms when the added stray inductance $L_{a}$ is 0 and $2 \mu \mathrm{H}$ are shown in Figure 10a,b, respectively. As shown in Figure 10, when the added stray inductance $L_{a}$ increases from 0 to $2 \mu \mathrm{H}, T_{c}$ increases from 66 to $346 \mu \mathrm{s}$, and $U_{\text {arc-avg }}$ increases from 11.7 to $15.8 \mathrm{~V}$. Both $T_{c}$ and $U_{\text {arc-avg }}$ increase with the increase of $L_{a}$. 


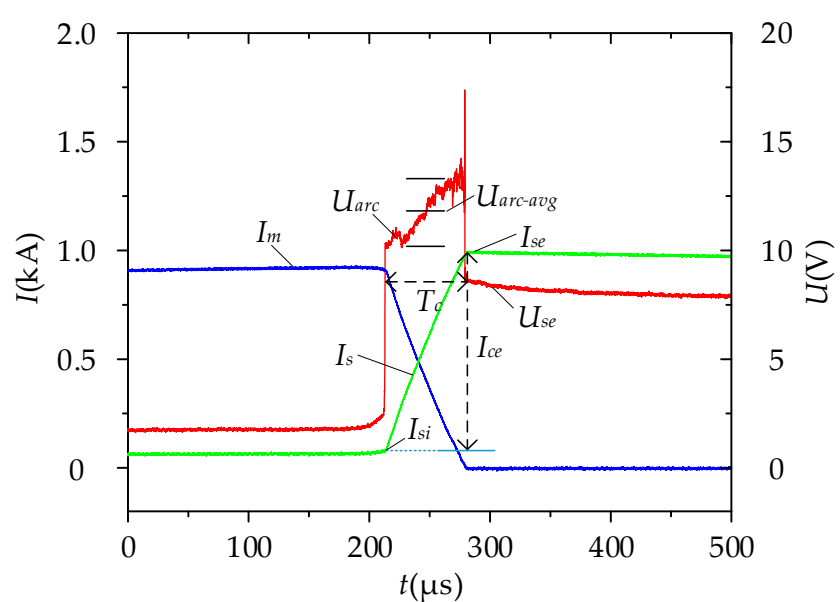

(a)

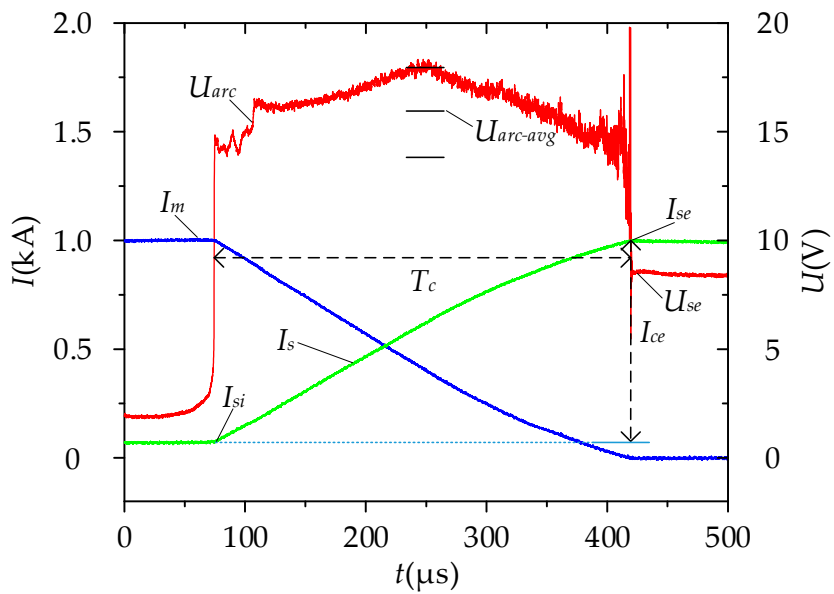

(b)

Figure 10. Waveforms of vacuum arc commutation when the added stray inductance $L_{a}$ is (a) 0 and (b) $2 \mu \mathrm{H}$.

When the added stray inductance $L_{a}$ ranges from 0 to $4 \mu \mathrm{H}$, the relationship curve between $T_{c}$ and $U_{\text {arc-avg }}$ and $L_{a}$ is shown in Figure 11. As shown in Figure 11, the relationship between $T_{c}$ and $L_{a}$ is approximately linear, which conforms to the law shown in Formula (9), and $U_{\text {arc-avg }}$ also increases with the increase of $L_{a}$, but the magnitude of the increase becomes smaller and smaller.

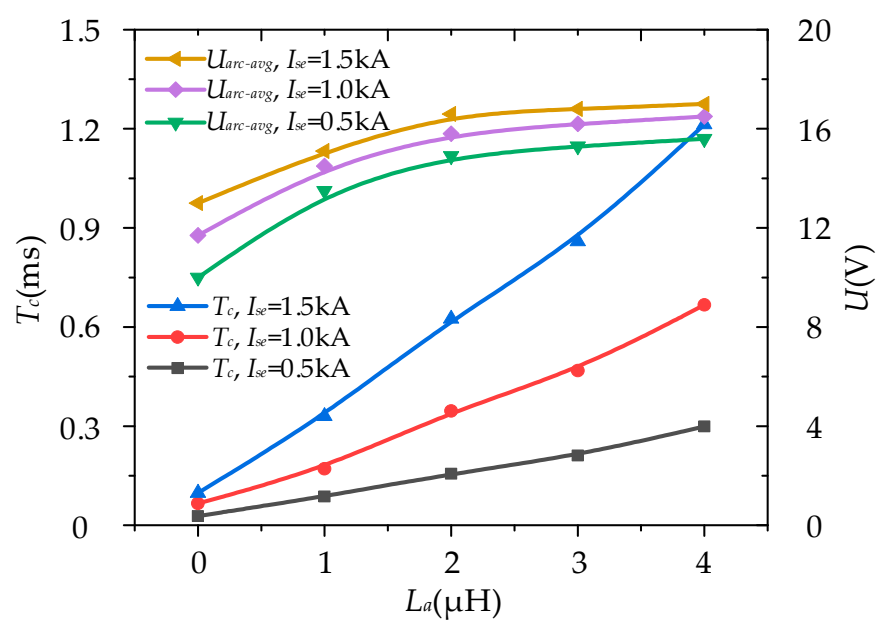

Figure 11. Curve of $T_{c}$ and $U_{\text {arc-avg }}$ with different stray inductances. 


\subsection{Influence of the Final Commutation Current}

Under the condition that $R_{a}$ is $2 \mathrm{~m} \Omega$, and $L_{a}$ is $0 \mu \mathrm{H}$, we obtained the waveforms of vacuum arc commutation with different commutation currents $I_{\mathcal{c} e}$. The waveforms when the commutation current $I_{\mathcal{c}}$ is 0.28 and $2.68 \mathrm{kA}$ are shown in Figure 12a,b, respectively. As shown in Figure 12, when the commutation current $I_{c e}$ increases from 0.28 to $2.68 \mathrm{kA}, T_{c}$ increases from 13 to $195 \mu \mathrm{s}, U_{\text {arc-avg }}$ increases from 9.2 to $12.9 \mathrm{~V}, U_{s e}$ increases from 2.7 to $11.8 \mathrm{~V}$, and $I_{s i}$ increases from 0.02 to $0.48 \mathrm{kA}$. All of $T_{\mathcal{C}}$, $U_{\text {arc-avg }}, U_{s e}$, and $I_{s i}$ increase with the increase of $I_{c e}$.

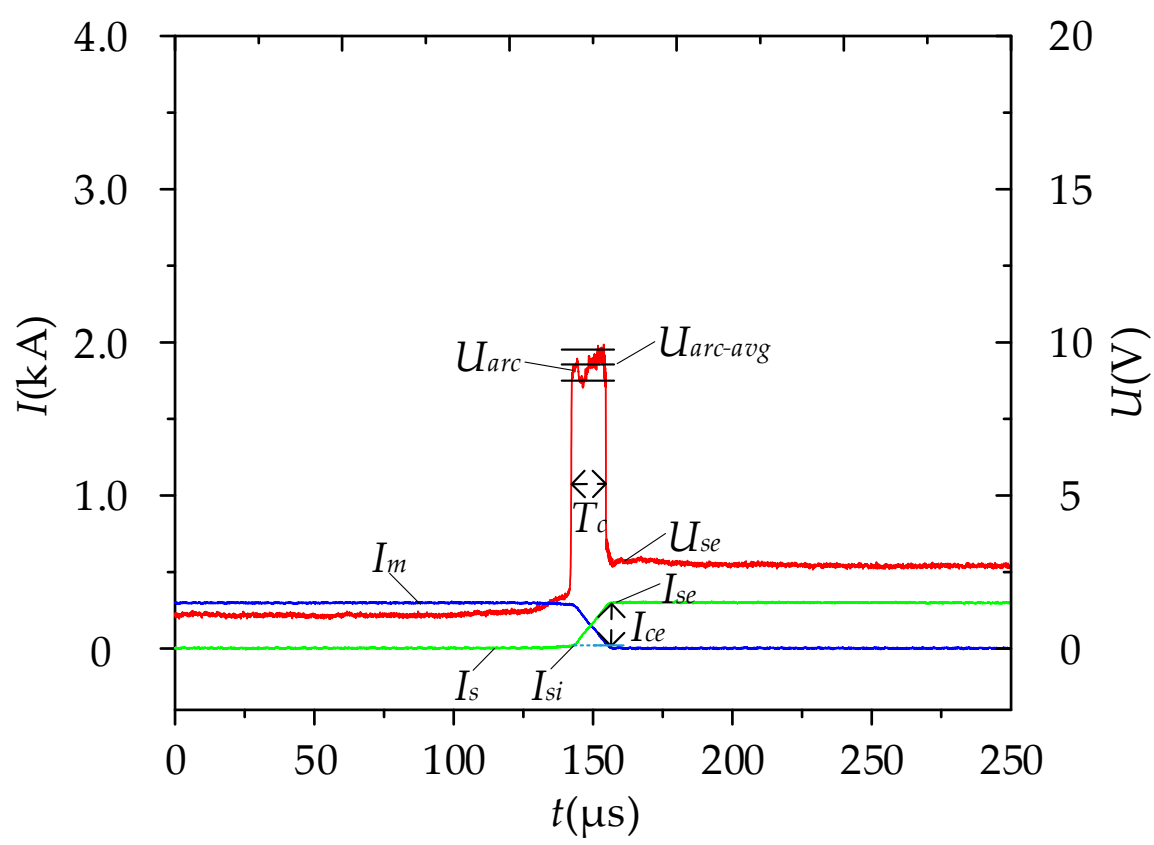

(a)

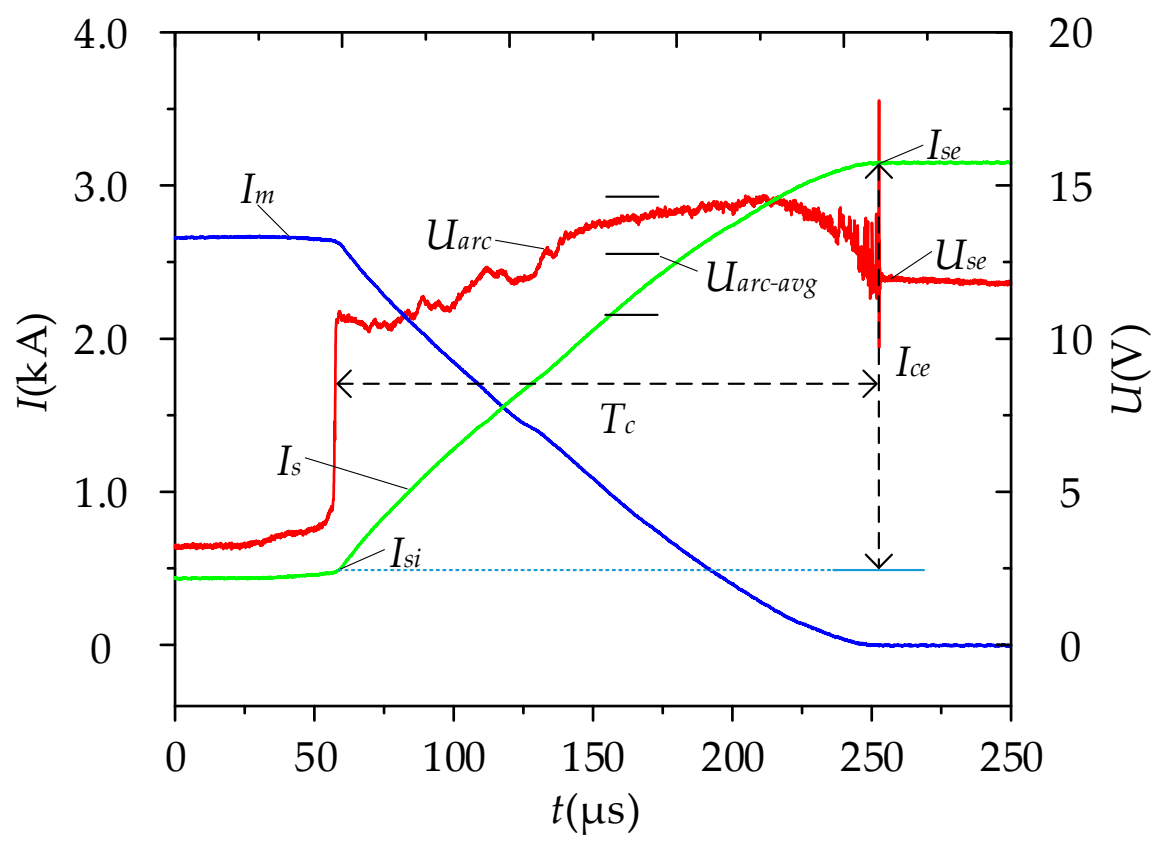

(b)

Figure 12. Waveforms of vacuum arc commutation when the final commutation current $I_{c e}$ is (a) 0.28 and (b) $2.68 \mathrm{kA}$. 
As shown in Figure 12, it is easy to know that changing $I_{c e}$ is achieved by changing $I_{s e}$. When the $I_{s e}$ ranges from 3.0 to $3.16 \mathrm{kA}$, the relationship curve between $U_{\text {arc-avg }}, U_{s e}, I_{c e}, I_{s i}$, and $I_{s e}$ is shown in Figure 13a. As shown in Figure 13a, all of $U_{a r c-a v g}, U_{s e}, I_{c e}$, and $I_{s i}$ increase with the increase of $I_{s e}$, and according to Figure 5 and Formula (7), as shown in Formula (13), the linear expressions between $U_{s e}$ and $I_{s e}$ and $U_{s i}$ and $I_{s i}$ can be obtained, respectively, and then we can get the calculation formula of $k$ about $U_{\text {arc-avg }}, U_{s e}$ and $U_{s i}$ :

$$
\left\{\begin{array}{l}
U_{s e}=U_{s 0}+R_{s} I_{s e}=2.0+3 I_{s e} \\
U_{s i}=U_{s 0}+R_{s} I_{s i}=2.0+3 I_{s i} \\
k=\frac{U_{a r c-a v g}-U_{s i}}{R_{s} I_{c e}}=\frac{U_{a r c-a v g}-U_{s i}}{U_{s e}-U_{s i}}
\end{array} .\right.
$$

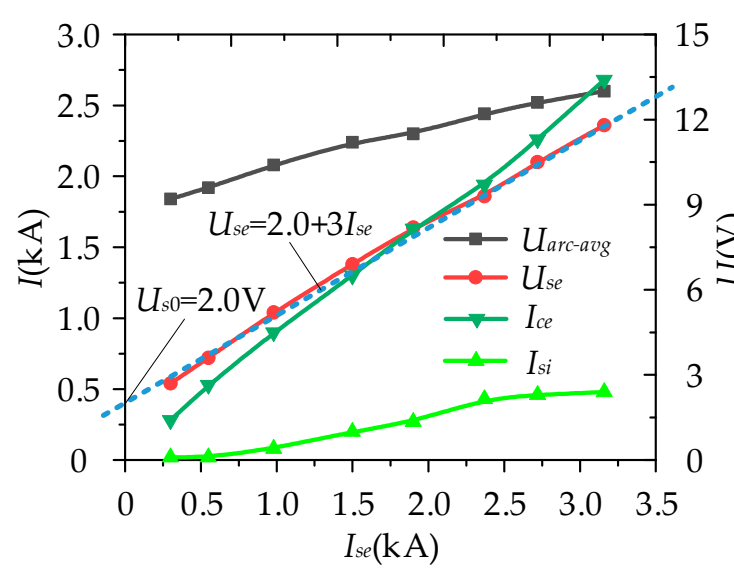

(a)

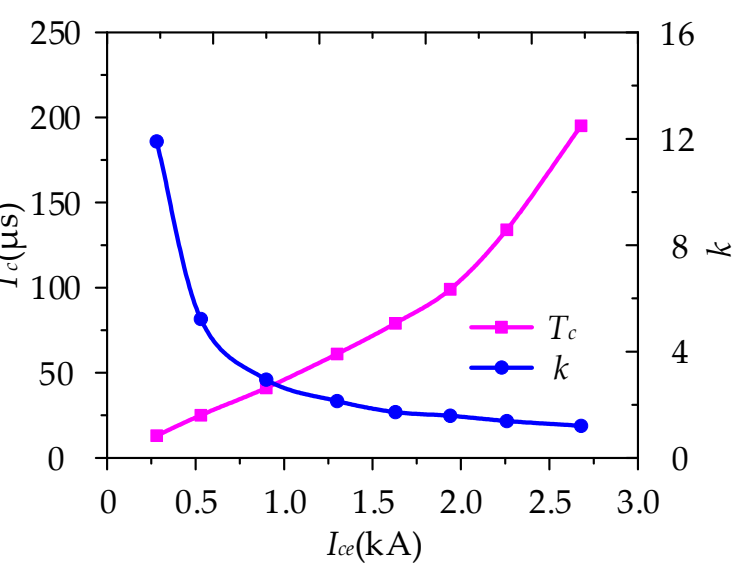

(b)

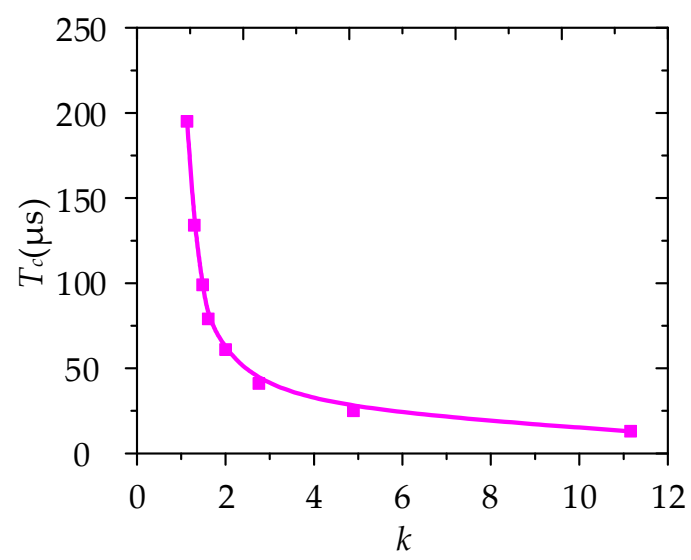

(c)

Figure 13. (a) The relationship curve between $U_{\text {arc-avg }}, U_{s e}, I_{c e}, I_{s i}$, and $I_{s e} ;(\mathbf{b})$ Curve of $T_{c}$ and $k$ with different final commutation currents; (c) The relationship curve between $T_{c}$ and $k$ in (b).

Therefore, according to Figure 13a and Formula (13), the $k$ value corresponding to different $I_{c e}$ values can be calculated, and the relationship curve between $k$ and $T_{c}$ and $I_{c e}$ is shown in Figure 13b. As shown in Figure 13b, $k$ decreases with the increase of $I_{c e}$, and the rate of decrease becomes slower and slower; $T_{c}$ increases with the increase of $I_{c e}$, and the rate of increase becomes faster and faster. The relationship curve between $T_{c}$ and $k$ was plotted according to Figure 13b, as shown in Figure 13c. It can be seen from Figure $13 c$ that $T_{c}$ decreases with increasing $k$, and the rate of decrease becomes slower and slower; the change law shown in Figure $13 \mathrm{c}$ basically coincides with the change law shown in Formula (11) and Figure 6. 


\subsection{Influence of the On-State Resistance of the SS}

Under the condition that $L_{a}$ is $0 \mu \mathrm{H}$, and $I_{c e}$ is approximately 1 and $2 \mathrm{kA}$, respectively, we obtained the waveforms of vacuum arc commutation with different on-state resistances. When the $I_{c e}$ is approximately $1 \mathrm{kA}$, the waveforms when the added on-state resistances $R_{a}$ is 0 and $9 \mathrm{~m} \Omega$ are shown in Figure 14a,b, respectively. Because when the added on-resistance is different, the value of $I_{s i}$ will also be different; so, to eliminate the impact of different $I_{s i}$, as shown in Figure 14, the IGBT module is turned on after the vacuum arc is generated, and in this case, $I_{s i}=0$ and $I_{c e}=I_{s e}$. As shown in Figure 14, when the added on-state resistances $R_{a}$ increases from 0 to $9 \mathrm{~m} \Omega, T_{c}$ increases from 34 to $99 \mu \mathrm{s}, U_{\text {arc-avg }}$ increases from 9.5 to $12.8 \mathrm{~V}$, and $U_{s e}$ increases from 3 to $12.1 \mathrm{~V}$. All of $T_{c}, U_{\text {arc-avg, }}$, and $U_{s e}$ increase with the increase of $R_{a}$. Meanwhile, it can be seen in Figure 14 that when the IGBT module is turned on, the vacuum arc voltage drops.

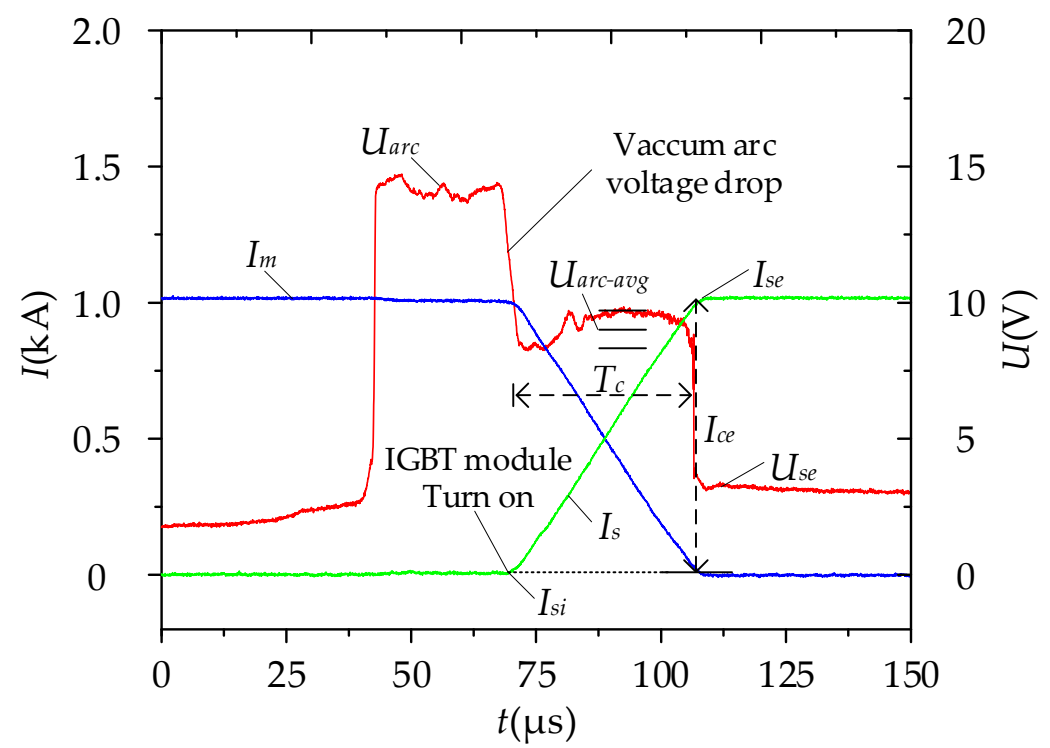

(a)

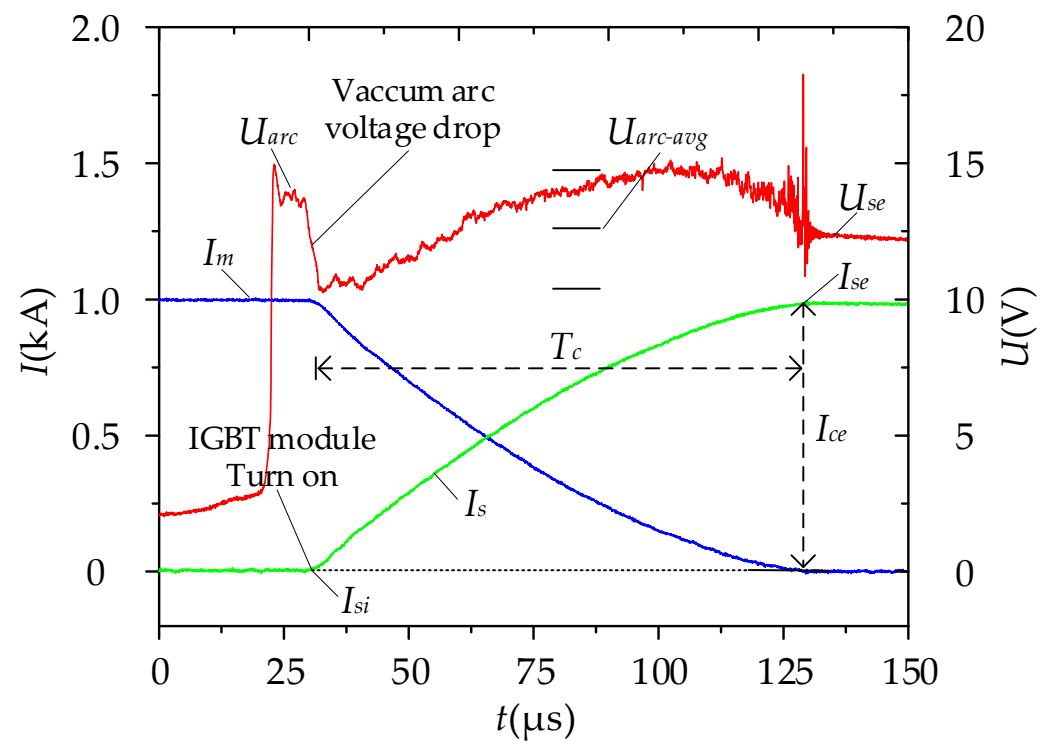

(b)

Figure 14. Waveforms of vacuum arc commutation when the added on-state resistances $R_{a}$ is (a) 0 and (b) $9 \mathrm{~m} \Omega$. 
When $I_{c e}$ is 1 and $2 \mathrm{kA}$, respectively, the relationship between $U_{\text {arc-avg }}, U_{s e}$, and $R_{a}$ is shown in Figure 15a. It can be seen from Figure $15 \mathrm{a}$ that whether $I_{c e}$ is 1 or $2 \mathrm{kA}$, both $U_{\text {arc-avg }}$ and $U_{s e}$ grow approximately linearly with $R_{a}$. As it is known from the previous section that $U_{s 0}=2.0$, and $I_{s i}=0$, we can easily get $U_{s i}=U_{s 0}+I_{s i} R_{s}=2.0$. Therefore, according to Figure 15a and Formula (13), the $k$ value corresponding to different $R_{a}$ values can be calculated, and the relationship between $k$ and $T_{c}$ and $R_{a}$ is shown in Figure $15 \mathrm{~b}$. It can be seen from Figure $15 \mathrm{~b}$ that whether $I_{c e}$ is 1 or $2 \mathrm{kA}, k$ decreases with the increase of $R_{a}$, and the rate of decrease becomes slower and slower; $T_{c}$ increases with the increase of $R_{a}$, and the rate of increase becomes faster and faster; the change law shown in Figure $15 \mathrm{~b}$ basically coincides with the change law shown in Figure 7. Meanwhile, when $R_{a}=0$, the corresponding $k_{0}$ value is 8.2 when the $I_{c e}$ is $1 \mathrm{kA}$, and the corresponding $k_{0}$ value is 4.3 when the $I_{c e}$ is $2 \mathrm{kA}$. The relationship curve between $T_{c}$ and $k$ was plotted according to Figure 15b, as shown in Figure 15c. It can be seen from Figure $15 c$ that $T_{c}$ decreases with increasing $k$, and the rate of decrease becomes slower and slower and even tends to be constant; the change law shown in Figure 15c basically coincides with the change law shown in Formula (12) and Figure 8.

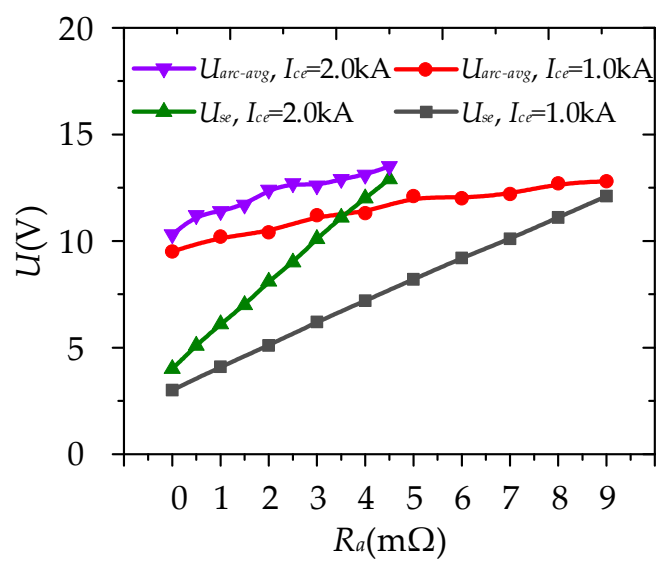

(a)

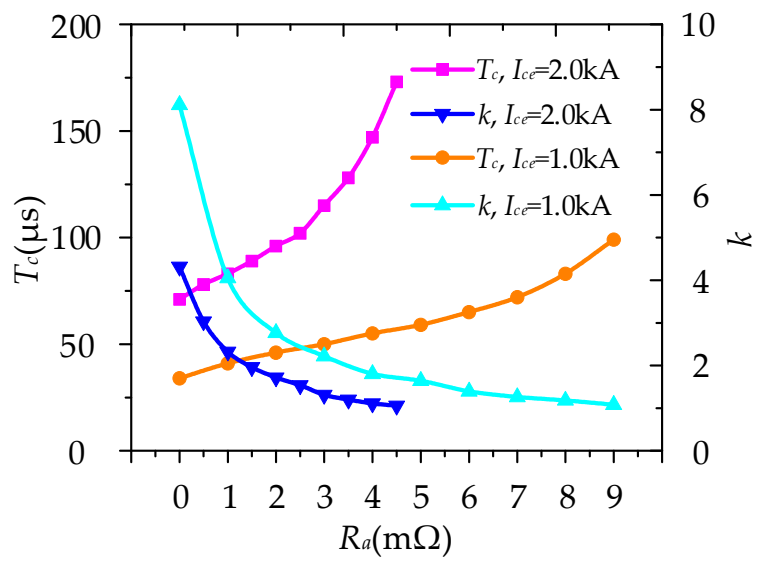

(b)

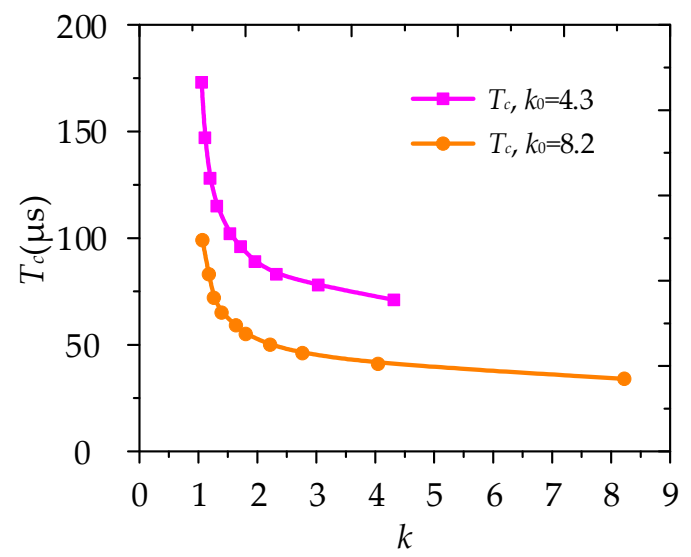

(c)

Figure 15. (a) Curve of $U_{\text {arc-avg }}$ and $U_{s e}$ with different on-state resistances; (b) Curve of $T_{\mathcal{c}}$ and $k$ with different on-state resistances; (c) The relationship curve between $T_{c}$ and $k$ in (b).

\section{Discussion}

\subsection{Vacuum Arc Commutation Coefficient}

Compared to the theoretical analysis and experiments above, it is easy to find that the experimental results can better match the theoretical Formulas (9)-(12). This shows that Formulas (9)-(12) can better reflect the influence of the main parameters, such as the vacuum arc voltage $U_{\text {arc }}$, final commutation 
current $I_{c e}$, on-state resistance $R_{s}$, and stray inductance $L_{s}$, on the vacuum arc commutation characteristics. Meanwhile, according to Formulas (11) and (12) and Figures 6, 8, 13c and 15c, the ratio $k$ of $U_{\text {arc-avg }}-U_{s i}$ to $R_{s} I_{c e}$ is a key parameter that affects $T_{c}$; and according to Formula (10), it is necessary to ensure that $k>1$ so that the current can be commutated to the SS branch. Overall, $k$ is a very important parameter during the vacuum arc commutation. Therefore, this paper defines $k$ as the vacuum arc commutation coefficient.

According to Figures $6,8,13 c$ and $15 c$, when $k$ is small, $T_{c}$ will increase significantly. Therefore, in order to reduce $T_{c}$, the value of $U_{\text {arc-avg }}-U_{s i}$ should be increased or the value of $R_{s} I_{c e}$ should be decreased. The main method of increasing the value of $U_{\text {arc-avg }}-U_{s i}$ is to increase the vacuum arc voltage. Applying an external magnetic field and connecting multiple MSs in series are currently common methods of increasing the arc voltage $[25,26]$. The main method to reduce the value of $R_{s} I_{c e}$ is to reduce the on-resistance $R_{s}$ and final commutation current $I_{c e}$, but reducing $I_{c e}$ will reduce the interrupting ability of NHCB. The method to reduce the on-resistance $R_{S}$ is to select FPEDs with low on-resistance or to increase the number of parallel FPEDs [27,28]. Meanwhile, it can be seen from Formula (9) and Figure 11 that reducing the stray inductance $L_{s}$ in the SS is also an effective method to reduce $T_{c}$.

\subsection{Influence of the Main Parameters on the Vacuum Arc Voltage}

It can be seen from the experiment that when the parameters $L_{s}, I_{c e}$, and $R_{s}$ increase, not only $T_{\mathcal{c}}$ increases but the vacuum arc voltage also increases, which is consistent with the positive feedback characteristics of the vacuum arc voltage. This can explain the sudden drop of the vacuum arc voltage in Figure 14, before the IGBT module is turned on, the vacuum arc commutation is very difficult, so the vacuum arc voltage at this time is higher. When the IGBT module is turned on, the difficulty of vacuum arc commutation decreases rapidly, so the vacuum arc voltage also decreases accordingly. Meanwhile, to better describe the influence of parameters $L_{s}, I_{\mathcal{c} e}$, and $R_{S}$ on $T_{\mathcal{C}}$, in the future work, the influence of the parameters $L_{S}, I_{c e}$, and $R_{S}$ on the vacuum arc voltage should be considered in Formula (9).

Although this paper focuses on NHCB, it is also applicable to other devices that use vacuum arc commutation, such as fault current limiters $[29,30]$. In the future work, further research will be conducted on other devices that use vacuum arc commutation.

\section{Conclusions}

In this paper, the vacuum arc commutation model of NHCB was established by simplifying SS and vacuum arc voltage, and the vacuum arc commutation characteristics of NHCB were studied through theoretical analysis and experiments. The mathematical expression of the relationship between the main parameters of the vacuum arc voltage, on-state resistance, and stray inductance and the duration of vacuum arc commutation was obtained.

The concept of the vacuum arc commutation coefficient was proposed based on the mathematical expressions and experiments, and it is a key parameter that influences the vacuum arc commutation characteristics. The value of the vacuum arc commutation coefficient should not be small; when it is small, the duration of vacuum arc commutation will increase significantly. Further, it is not the bigger the better, as when it is bigger, the duration of vacuum arc commutation will decrease slowly. Meanwhile, it must always be ensured that the value of the vacuum arc commutation coefficient is greater than one, so that the current can be commutated to the SS branch.

In the process of vacuum arc commutation, when the difficulty of vacuum arc commutation increases, the vacuum arc voltage will also increase, and from the extremely difficult vacuum arc commutation to the easier vacuum arc commutation, the vacuum arc voltage will also be reduced immediately. This paper can provide the theoretical foundation for the structure and parameter optimization of NHCB and other devices using vacuum arc commutation. 
Author Contributions: D.W. and M.L. contributed to the research idea. D.W., X.D. and J.Z. designed the experiments. D.W. worked on the theoretical analysis, data analysis and drafted the manuscript. R.W. and T.L. helped to do the experiments. J.Q. and J.L. worked on editing and revising of the manuscript. All authors have read and agreed to the published version of the manuscript.

Funding: This research was funded in part by the National Natural Science Foundation of China (No. 51777025) and in part by the Fundamental Research Funds for the Central Universities (No. DUT19ZD219).

Conflicts of Interest: The authors declare no conflict of interest.

\section{References}

1. Chen, Z.; Yu, Z.; Zhang, X.; Wei, T.; Lyu, G.; Qu, L.; Huang, Y.; Zeng, R. Analysis and Experiments for IGBT, IEGT, and IGCT in Hybrid DC Circuit Breaker. IEEE Trans. Ind. Electron. 2018, 65, 2883-2892. [CrossRef]

2. Martin, B.; Jens, W.; Steffen, B. Comparison of IGCT and IGBT for the use in the modular multilevel converter for HVDC applications. In Proceedings of the IEEE 9th International Multi-Conference on Systems, Signals and Devices, Chemnitz, Germany, 20-23 March 2012.

3. Bernet, S.; Teichmann, R.; Zuckerberger, A.; Steimer, P. Comparison of high-power IGBT's and hard-driven GTO's for high-power inverters. IEEE Trans. Ind. Appl. 1999, 35, 487-497. [CrossRef]

4. Zhou, Y.; Huang, Y.; Pang, J.; Wang, K. Remaining useful life prediction for supercapacitor based on long short-term memory neural network. J. Power Sources 2019, 440, 227149. [CrossRef]

5. Geider, P.V.; Ferreira, J.A. Zero volt switching hybrid DC circuit breakers. In Proceedings of the IEEE Industry Applications Society Annual Meeting, Rome, Italy, 8-12 October 2000; Volume 5, pp. 2923-2927.

6. Ahmad, M.; Wang, Z. A Hybrid DC Circuit Breaker with Fault-Current-Limiting Capability for VSC-HVDC Transmission System. Energies 2019, 12, 2388. [CrossRef]

7. Swati, R.; Devenkumar, K.; Chragkumar, D.; Subrata, P. Development of a Prototype Hybrid DC Circuit Breaker for Superconducting Magnets Quench Protection. IEEE Trans. Appl. Supercond. 2014, 24, 4702006.

8. Gu, C.; Wheeler, P.; Castellazzi, A.; Watson, A.J.; Effah, F. Semiconductor Devices in Solid-State/Hybrid Circuit Breakers: Current Status and Future Trends. Energies 2017, 10, 495. [CrossRef]

9. Zhang, X.; Yu, Z.; Zhao, B.; Chen, Z.; Lyu, G.; Huang, Y.; Zeng, R. A Novel Mixture Solid-State Switch Based on IGCT With High Capacity and IGBT With High Turn- OFF Ability for Hybrid DC Breakers. IEEE Trans. Ind. Electron. 2020, 67, 4485-4495. [CrossRef]

10. Nadeem, M.H.; Zheng, X.; Tai, N.; Gul, M. Identification and Isolation of Faults in Multi-terminal High Voltage DC Networks with Hybrid Circuit Breakers. Energies 2018, 11, 1086. [CrossRef]

11. Callavik, M.; Blomberg, A.; Häfner, J.; Jacobson, B. Break-through!: ABB's hybrid HVDC breaker, an innovation breakthrough enabling reliable HVDC grids. ABB Rev. 2013, 2, 7-13.

12. Meyer, J.M.; Rufer, A. A DC hybrid circuit breaker with ultra-fast contact opening and integrated gate-commutated thyristors (IGCT). IEEE Trans. Power Del. 2006, 21, 646-651. [CrossRef]

13. Genji, T.; Nakamura, O.; Isozaki, M.; Yamada, M.; Morita, T.; Kaneda, M. 400V class high-speed current limiting circuit breaker for electric power system. IEEE Trans. Power Del. 1994, 9, 1428-1435. [CrossRef]

14. Polman, H.; Ferreira, J.; Kaanders, M.; Evenblij, B.; Gelder, P. Design of a bi-directional 600V/6kA ZVS hybrid DC switch using IGBTs. Ind. Appl. Conf. 2001, 2, 1052-1059.

15. Novello, L.; Baldo, F.; Ferro, A.; Maistrello, A.; Gaio, E. Development and Testing of a 10-kA Hybrid Mechanical-Static DC Circuit Breaker. IEEE Trans. Appl. Supercond. 2011, 21, 3621-3627. [CrossRef]

16. Lv, G.; Zeng, R.; Huang, Y.; Chen, Z. Researches on $10 \mathrm{kV}$ DC hybrid circuit breaker based on IGCT series. Chin. Soc. For Elec. Eng. 2017, 37, 1012-1020.

17. Roodenburg, B.; Taffone, A.; Gilardi, E.; Tenconi, S.M.; Evenblij, B.H.; Kaanders, M.A.M. Combined ZVS-ZCS topology for high-current direct current hybrid switches: Design aspects and first measurements. IET Electr. Power Appl. 2007, 1, 183-192. [CrossRef]

18. Liao, M.; Wang, D.; Leng, T.; Duan, X.; Wang, R. Effect of Adding Impedance for Current Balancing on the Vacuum Arc Commutation Characteristics of DC Microgrid Hybrid Circuit Breakers. IEEJ Trans. 2020, 15, 676-683. [CrossRef]

19. Liao, M.; Huang, J.; Ge, G.; Duan, X.; Huang, Z.; Zou, J. Vacuum arc commutation characteristics of the DC microgrid hybrid circuit breakers. IEEE Trans. Plasma Sci. 2017, 45, 2172-2178. [CrossRef] 
20. Wen, W.; Huang, Y.; Sun, Y.; Wu, J.; Mohmmad, A.; Liu, W. Research on Current Commutation Measures for Hybrid DC Circuit Breakers. IEEE Trans. Power Del. 2016, 31, 1456-1463. [CrossRef]

21. Dong, E.; Zhang, L.; Wang, S.; Qin, T.; Zou, J.; Liu, J. Research on Internal and External Factors Affecting Current Commutation in Vacuum. In Proceedings of the 28th International Symposium on Discharges and Electrical Insulation in Vacuum (ISDEIV 2018), Greifswald, Germany, 23-28 September 2018; Volume 1, pp. 279-282.

22. Felipe, F.; Rodrigo, A.; Steffen, B. Comparison of 4.5-kV press-pack IGBTs and IGCTs for medium-voltage converters. IEEE Trans. Ind. Electron. 2013, 60, 440-449.

23. Auerbach, F.; Bauer, M.; Gottert, J.; Hierholzer, M.; Porst, A.; Reznik, D.; Schulze, H.; Schulze, T.; Spanke, R. $6.5 \mathrm{kV}$ IGBT-modules. In Proceedings of the IEEE industry applications society annual meeting, Phoenix, AZ, USA, 3-7 October 1999; Volume 3, pp. 1770-1774.

24. Alferov, D.F.; Ivanov, V.P.; Sidorov, V.A. DC vacuum arc in a Performance of a nonuniform axisymmetric magnetic field. High Temp. 2006, 44, 342-355. [CrossRef]

25. Alferov, D.F.; Ivanov, V.P.; Sidorov, V.A. Characteristics of DC vacuum arc in the transverse axially symmetric magnetic field. IEEE Trans. Plasma Sci. 2003, 31, 918-922. [CrossRef]

26. Zabello, K.K.; Barinov, Y.A.; Chaly, A.M.; Logatchev, A.A.; Shkolnik, S.M. Experimental study of cathode spot motion and burning voltage of low-current vacuum arc in magnetic field. IEEE Trans. Plasma Sci. 2005, 33, 1553-1559. [CrossRef]

27. Letor, R. Static and dynamic behavior of paralleled IGBTs. IEEE Trans. Ind. Appl. 1992, 28, 395-402. [CrossRef]

28. Shammas, N.Y.A.; Withanage, R.; Chamund, D. Optimisation of the number of IGBT devices in a series-parallel string. Microelectron. J. 2008, 39, 899-907. [CrossRef]

29. Pedrow, P.D.; Burrage, L.M.; Shohet, J.L. Performance of a Vacuum Arc Commutating Switch for a Fault-Current Limiter. IEEE Power Energy Mag. 1983, 5, 1269-1277.

30. Khan, U.F.; Lee, J.; Amir, F.; Lee, B. A Novel Model of HVDC Hybrid-Type Superconducting Circuit Breaker and Its Performance Analysis for Limiting and Breaking DC Fault Currents. IEEE Trans. Appl. Supercond. 2015, 25, 1-9. [CrossRef] 